\title{
Tradeoffs in Jet Inlet Design: A Historical Perspective
}

\author{
András Sóbester* \\ University of Southampton, Southampton, SO17 1BJ Hampshire, United Kingdom
}

DOI: $10.2514 / 1.26830$

\begin{abstract}
The design of the inlet(s) is one of the most demanding tasks of the development process of any gas turbine-powered aircraft. This is mainly due to the multi-objective and multidisciplinary nature of the exercise. The solution is generally a compromise between a number of conflicting goals and these conflicts are the subject of the present paper. We look into how these design tradeoffs have been reflected in the actual inlet designs over the years and how the emphasis has shifted from one driver to another. We also review some of the relevant developments of the jet age in aerodynamics and design and manufacturing technology and we examine how they have influenced and informed inlet design decisions.
\end{abstract}

\section{Introduction}

$\mathbf{T}$ HE seminal intake aerodynamics text by Seddon and Goldsmith [1] summarizes the problem of air intake design as ensuring that "an aircraft engine is properly supplied with air under all conditions of aircraft operation and that the aptitude of the airframe is not unduly impaired in the process." The definition of what is considered a "proper" air supply, the conditions of operation and their analysis, as well as the various facets of "airframe aptitude" and our understanding of them have changed significantly since the early days of jet aircraft design. Nevertheless, the problem statement itself has always been valid and it hints at the multidisciplinary and multiobjective nature of intake design.

The various aspects of the engine air supply, as well as the many factors that influence the aptitude of the airframe form a large set of competing objectives and constraints. The relative importance of these design drivers and the precise roles they take in this optimization framework change from one project to another. For example, the objective could be to maximize performance, while meeting a maximum allowable intake noise constraint (dictated by operational requirements, regulations, stealth considerations, etc.). Equally, another project might aim to minimize life cycle cost, while meeting performance and environmental targets. Either way, a good understanding of the intricate relationships between these criteria has always been the sine qua non of a good design. \pm

In what follows we review these drivers, highlighting the most important relationships between them. Our intention here is not to delve into their technicalities or provide an exhaustive survey of the state of the art for each; the reader seeking such information will be served well by a number of existing texts and reviews. Instead, we aim to chart the scientific and technical developments of the jet age that have influenced the engineering tradeoffs between these factors and provide the reader with a set of key references that could serve as starting points for more in-depth study. The developments in question are not confined to a better understanding of the aerodynamics, aeroacoustics, and structural dynamics involved, but also include advances in design and manufacturing technology: the advent of computational modeling, composite materials, stereolitography, etc. At the same time, by way of illustration, we shall also examine the impact these developments have had on actual inlet designs.

Before we proceed with our historical survey, let us make two technical points. Firstly, an issue of English usage. Some authors

Received 27 July 2006; revision received 19 January 2007; accepted for publication 24 January 2007. Copyright (C) 2007 by the author. Published by the American Institute of Aeronautics and Astronautics, Inc., with permission. Copies of this paper may be made for personal or internal use, on condition that the copier pay the $\$ 10.00$ per-copy fee to the Copyright Clearance Center, Inc., 222 Rosewood Drive, Danvers, MA 01923; include the code 0021-8669/07 \$10.00 in correspondence with the CCC.

*Lecturer, Computational Engineering and Design Group. Member AIAA. prefer the term "inlet," whereas others use "intake." We use both, interchangeably, not wishing to obscure the main message by issues of semantics. Secondly, a note on the scope of this work: we focus on intakes of turbojet- and turbofan-powered fixed-wing aircraft. This is mostly a reflection of the author's own research interests and personal experience, rather than a statement of their relative importance.

\section{Design Drivers}

The design of airbreathing propulsion systems almost always involves having to deal with the mismatch between the flow conditions in the freestream and those required by the engine at the entrance to the fan or compressor. Achieving the required transformation is the central role of the inlet and the efficiency of this process is the main objective that drives its design. An inlet is said to be efficient if a large proportion of the available freestream total pressure is recovered at the compressor entrance. A good inlet design will thus maximize pressure recovery, while at the same time minimizing drag, fan face pressure distortions, weight, complexity, and cost, and satisfying a number of other constraints. In the sections that follow we look at these objectives and constraints and the relationships between them. We start with a pair of objectives that are in conflict most of the time and thus present the designer with the fundamental tradeoff of inlet design.

\section{A. Pressure Recovery and Drag}

A significant source of pressure loss is the friction on external surfaces wetted by the flow going into the inlet. The designers of most of the early jet aircraft chose to eliminate this entirely through pitot-type installations, either by placing the engines on the wings, far from the fuselage (Messerschmitt Me-262, Arado Ar-234, Gloster Meteor) or, on single-engine models, by simply placing the intake in the nose (see Fig. 1 for three prominent examples). Although such arrangements allowed the capture of clean, freestream air, it became apparent as early as the end of the first decade of jetpropelled flight that this type of installation on single-engine jets was taking up too much precious space in the fuselage (we shall return later to the issue of fuselage space constraints). Mounting twin intakes on the side of the fuselage, which was the logical solution to the fuselage space problem, focused the interest of the aeronautics community to understanding the balance between good pressure recovery and low inlet drag.

On the one hand, "scoop"-type designs offered good pressure recovery with a likely drag penalty, whereas flush-mounted

†This is highlighted by those cases in which a thorough understanding of certain design drivers only emerged as late as the prototype or production stage, when any adjustment is bound to be costly. Examples include the General Dynamics F-111A, where engine surges made a major inlet redesign inevitable [2] or the Boeing 727, where the S-duct of the central engine had to be redesigned for similar reasons [3] . 

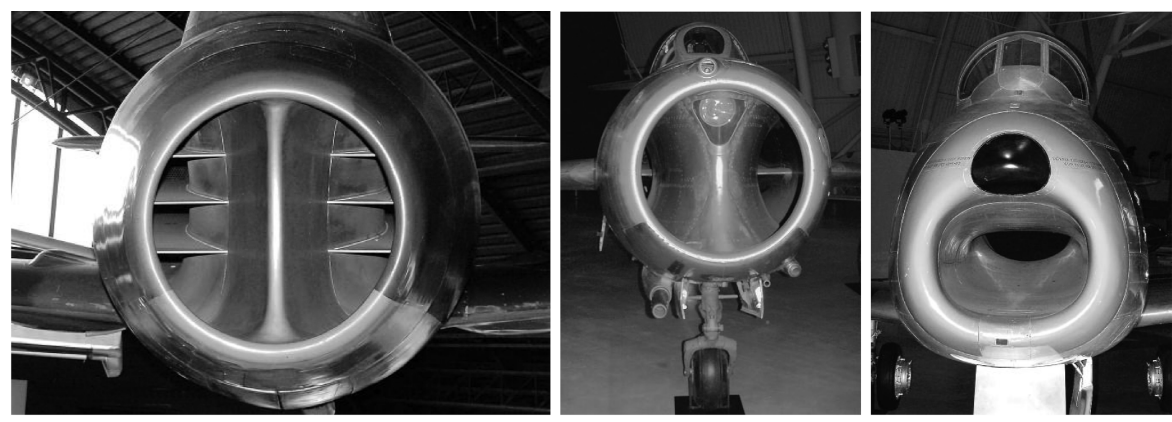

Fig. 1 Nose-mounted pitot intakes of the dawn of the jet age (from left to right): Gloster E28/39 (1941), MiG-15bis (1947), and F-86A Sabre (1947).
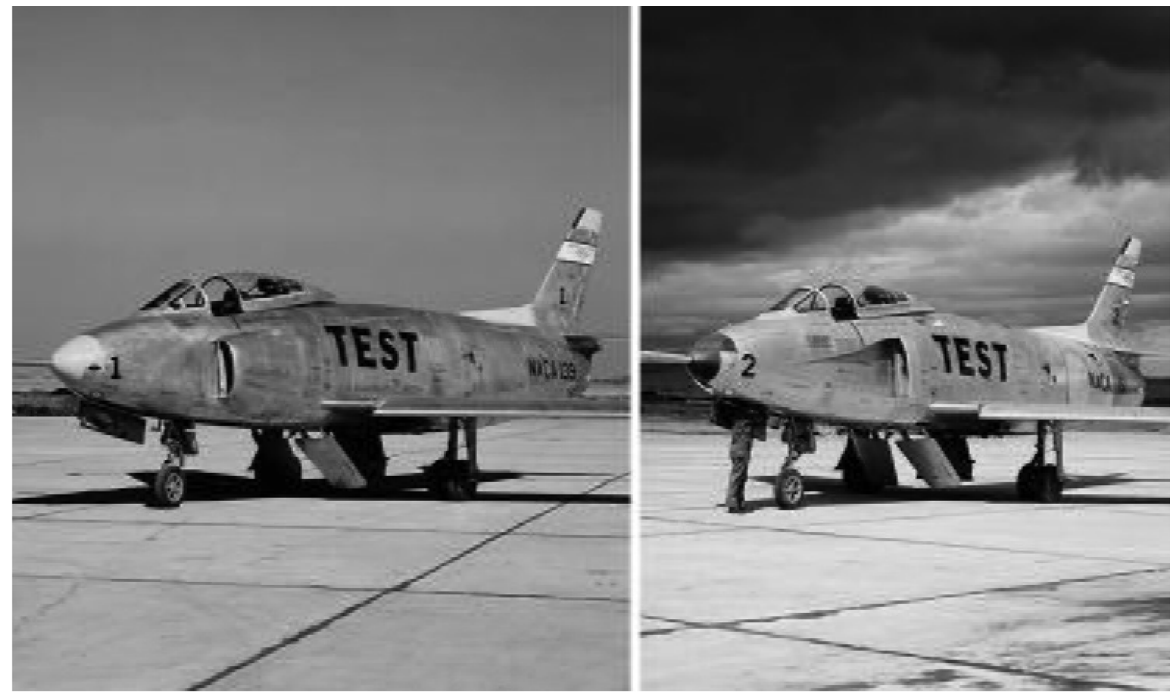

Fig. 2 NACA's North American YF-93A research aircraft, with scoop intakes on number one (left) and submerged (flush) intakes on number two (NACA photos, 1951).

"submerged" intakes, though potentially compromising pressure recovery, did not add to the cross-sectional area of the fuselage and were therefore seen as a low-drag solution. The first thorough studies on the latter type were conducted by NACA in the 1950s; indeed, flush intakes are, to this day, almost universally known as "NACA intakes." In a 1951 technical note, Sacks and Spreiter [4] drew attention to the effects of boundary layer ingestion on the pressure recovery of flush intakes, noting also the importance of the vortex sheets forming along the edges of the intake. Their most significant observation was that the intake side wall boundary layer losses are very small compared to the boundary layer losses on the approach ramp (two decades later Ward-Smith [5] was to build an analytical flow model based, to a large extent, on these results, allowing more accurate efficiency calculations on NACA intakes).

Subsequent research confirmed the importance of proper boundary layer handling on other types of intakes as well. Indeed, as Seddon and Goldsmith [1] note, historically, most of the intake development problems have been attributable in one way or another to the behavior of the boundary layer in the hostile environment of the adverse pressure gradient accompanying the retardation of the flow (we shall discuss the evolution of boundary layer treatment technologies in more detail later on).

Returning to the early NACA work on flush intakes, an improving understanding of their aerodynamics had still not provided sufficient design guidance with regards to the drag vs pressure recovery tradeoff. Flight tests were therefore conducted, using two North American YF-93A aircraft, one fitted with scoop intakes, the other with flush intakes (Fig. 2). Drag and ram pressure recovery measurements were taken on both aircraft at various power settings at constant Mach number, resulting in different engine mass flow rates. The altitude was varied accordingly between 22,000 and $27,000 \mathrm{ft}$. The results were quite interesting. The difference in overall drag between the two aircraft was rather modest, with the scoop inlet being marginally better up to Mach 0.89 and the flush intake causing lower drag at the high end of the subsonic range. However, for low Mach numbers the submerged intake showed better pressure recovery, with the scoop intake being more efficient above Mach 0.87. From an aircraft performance point of view, based on the differences between gross engine thrust and drag of the two aircraft, NACA concluded that there was little to choose between the two

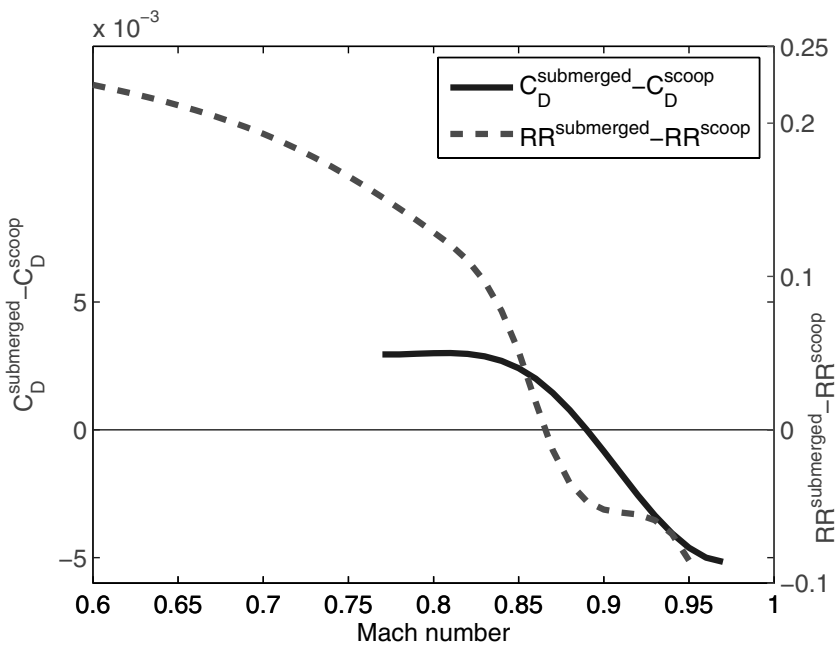

Fig. 3 Differences in the drag coefficients $C_{D}$ and ram recoveries (RR denotes the ratio of the ram pressure at the compressor face and at the intake entrance) of the two aircraft shown in Fig. $\underline{2}$ (plot generated from data contained in [6]). 


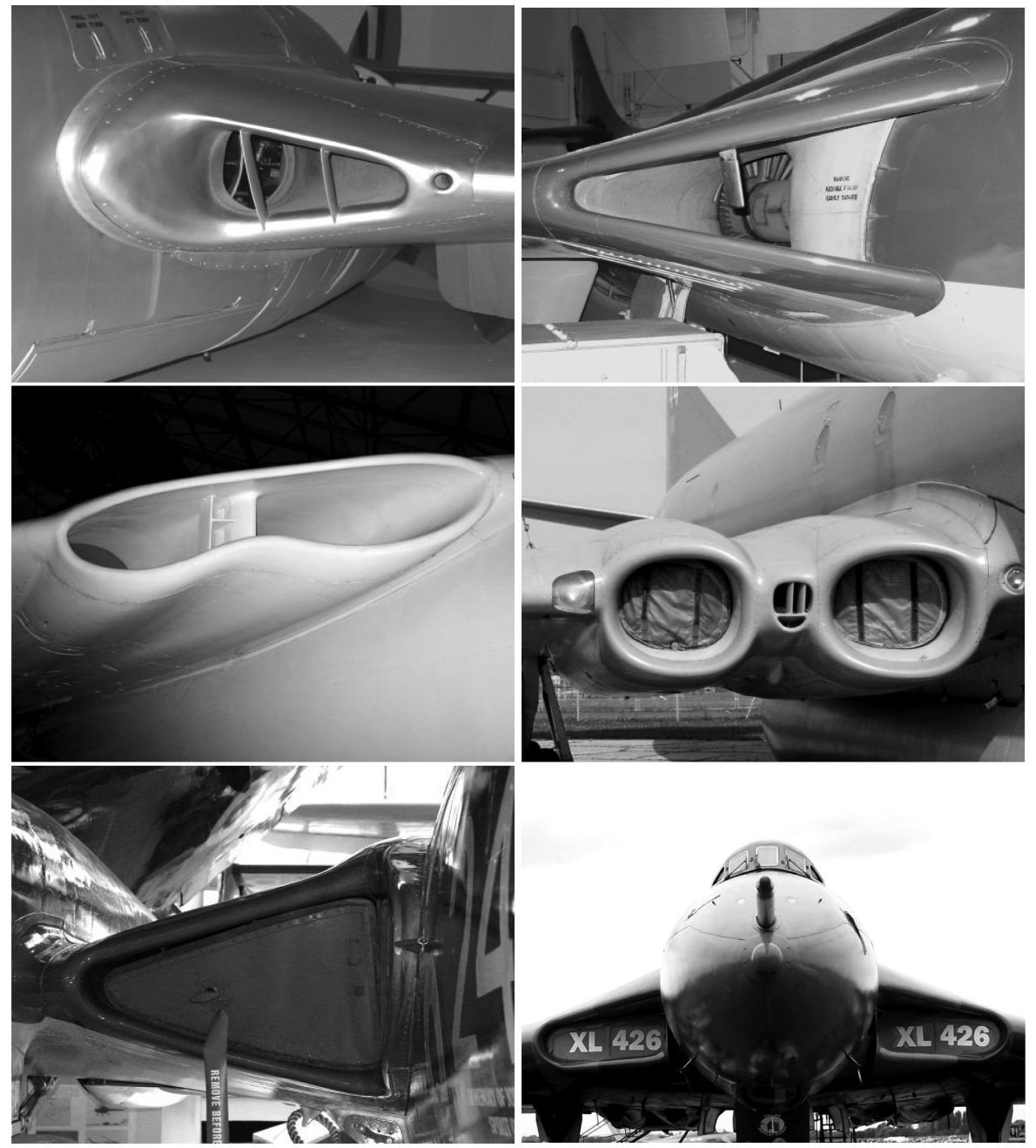

Fig. 4 Wing-root, leading-edge intakes on British aircraft, clockwise from top left: De Havilland Vampire F3 (1946), Hawker Hunter FGA9 (1954), BAE Systems (Hawker-Siddeley) Nimrod MR.2 (1969, intake design virtually identical to the 1949 de Havilland Comet), Avro Vulcan (1956), Sea Vixen (1958), and Vickers Valiant (1951).

types of installations throughout the Mach number range under consideration. Figure $\underline{3}$ summarizes some of the data contained in the seminal Research Memorandum by Stewart Rolls [6] that reported the previous findings in 1953. The results of these flight tests have almost certainly contributed to the demise of the NACA flush intake as a main source of air on fast jet aircraft.

A different early design outcome of the drag vs pressure recovery vs fuselage space balancing act was the wing leading-edge installation of jet intakes. Especially popular in Britain, wing root intakes appeared as early as 1946, on the De Havilland Vampire (and later, on its improved version, the Venom) and, with slight variations, on other fighters (Hawker Hunter, 1954), bombers (Vickers Valiant, 1951, Avro Vulcan, 1956) and the de Havilland Comet airliner (1949); see Fig. 4 for examples. Eventually, increasing speeds and thus increasing sweep angles spelled the end of the wing root intake. In the late 1950s, Hawker engineers working on the prototype P1127 noticed that intakes with swept faces (not only those mounted in wing roots) had high spillage drag, because most of the excess airflow tended to spill out at the most rearward part of the intake, instead of being uniformly distributed along the lip, a more benign situation from the drag viewpoint.

Additionally, pressure losses were observed at low speeds, which were also attributed to the sweepback effect: most of the air drawn in by the engine was entering through the rearmost section [7]. The more aft lip surfaces of such intakes have to do the bulk of the airflow turning (either when sucking or spilling excess air), leading to overspeed and shock losses: deteriorating both the average value and the uniformity of the pressure recovery. In fact, similar considerations (backed up by numerical flow analysis) led British Aerospace engineers to desweep the intake lips of the Nimrod MRA.4 (note that their starting point, the earlier MR.2, had intake faces swept at $25 \mathrm{deg}$, same as the wing leading edge, which they thus were an integral part of; see Fig. 4). Reference [8] contains an informative account of the Nimrod intake development process.

The advent of supersonic aircraft powered by airbreathing engines opened up a new set of challenges for intake designers. A rule of thumb often used is that $1 \%$ pressure loss reduces thrust by $1 \%$, but it became clear early on that the thrust loss caused by pressure losses in supersonic flight increases nonlinearly. For example, at a flight speed of Mach 2.2, a typical engine losing $8 \%$ of the freestream total pressure through the intake will suffer a reduction in thrust of $13 \%$ and a 5\% increase in fuel consumption [9]. Since the mid-1950s, when this first became evident, a tremendous amount of research effort has gone into the study of supersonic intake pressure recovery and drag.

Though it is not our intention to delve into their details, it is worth pausing to ponder some of the complex tradeoffs highlighted by this research effort. The designs developed along the way provide the best reflection of just how intricate these tradeoffs are, mostly through their slow (or nonexistent) convergence towards any particular technological solution. Consider, for example, one of the earliest flavors such intakes came in, that of the annular variety with a conical bullet center body as a means of generating the oblique shock waves meant to retard the flow before it enters the engine. A typical, early example is the MiG-21 (1956), shown on the left of Fig. 5. In spite of the rapid rise of the popularity of the 2-D (rectangular) mixed 

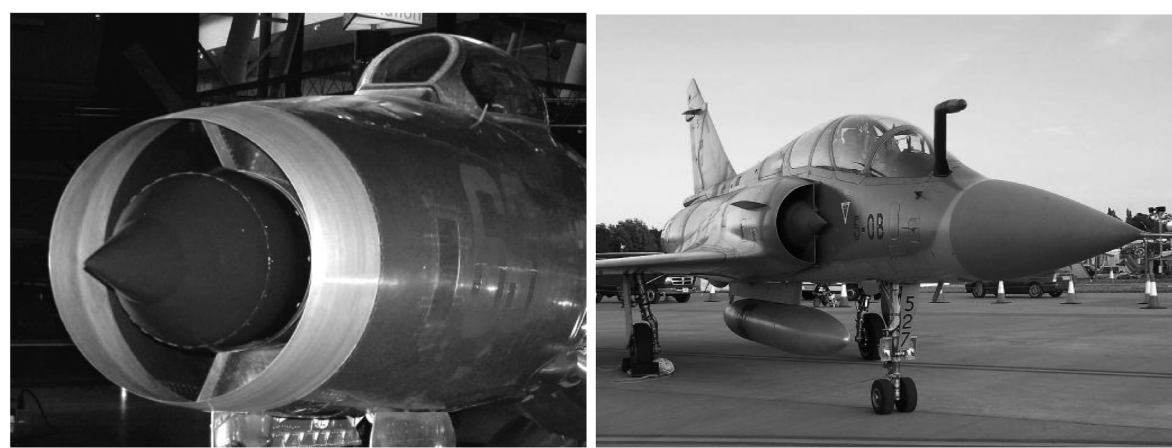

Fig. 5 Annular intakes and bullet centerbodies on the 1956 MiG-21F (left) and the 1978 Mirage 2000 (right).
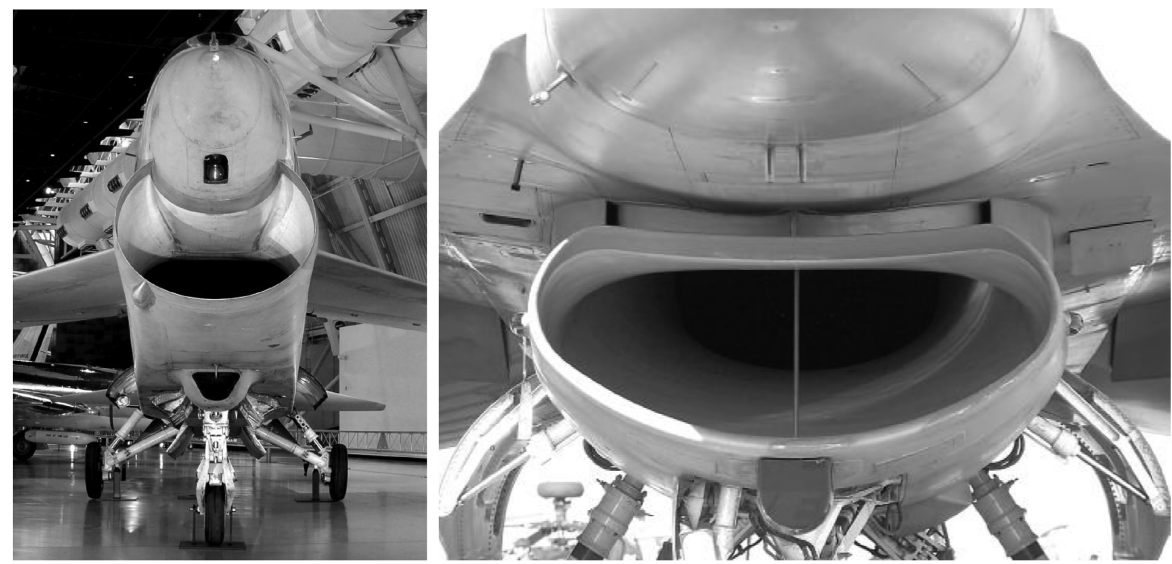

Fig. 6 Normal shock intakes on the Vought F-8 and the General Dynamics/Lockheed Martin F-16BM.

or external compression intake in years to come [the Mach 2.34 Grumman F-14 Tomcat (1974), the Mach 2.5 McDonnel-Douglas F15 Eagle (1976), the Mach 2.3 Panavia Tornado (1974), etc.; see Fig. 10], the conical bullet was still the defining feature of the annular intake of the Mach 2.2 Mirage 2000 in 1978 (pictured on the righthand side of Fig. 5). Possible explanations here stem from having to consider other design drivers: annular intakes are more efficient from a structural and thus weight standpoint, whereas rectangular intakes present a lower risk of surge in asymmetric flow conditions [10], less distortion at high angles of attack, and offer better geometry variation possibilities than a translating or collapsing conical bullet (generally used on annular intakes).

Similarly, no definitive answer exists to the question of how many shocks should be generated. Though theoretically a large number of weak shocks is preferable to a small number of strong ones (in fact, the aerodynamic ideal is the so-called isentropic inlet, featuring an infinity of weak shocks), in practice a single, normal shock can provide the best pragmatic design solution ("normal" here refers to the position of the shock wave relative to the airflow entering the intake). This is certainly the case at relatively low supersonic Mach numbers (Vought F-8 Crusader, Mach 1.2, Fig. 6, left), but,

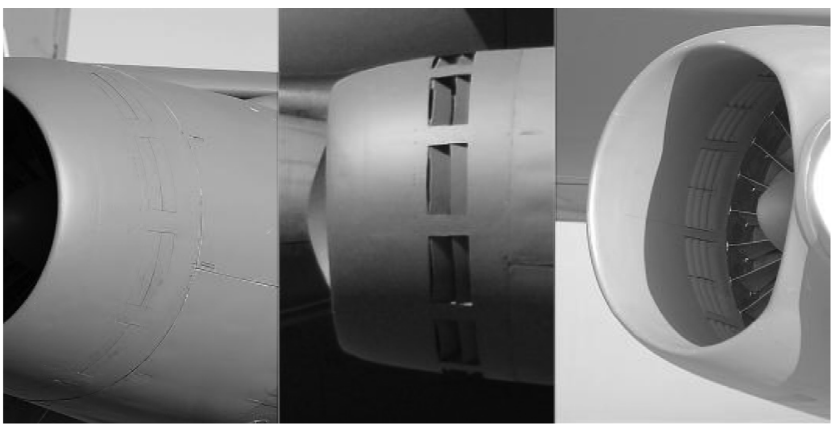

Fig. 7 Blow-in doors on the B-52H: closed (left), open (center), and view from inside the nacelle (right). somewhat surprisingly, the simple, fixed-geometry normal shock intake was also the choice of the General Dynamics engineers when designing the lightweight fighter concept that was later to become the Mach 2.05 F-16 Fighting Falcon (see Fig. 6, right). The reader may suspect here that cost considerations have swayed them in this direction, but, in an article written in 1976, Hawkins [11] argued that this would have been the optimum configuration even if cost had not been an objective, as a variable geometry intake, whereas permitting a top Mach number of 2.2 would have incurred a $4 \%$ acceleration time penalty (from Mach 0.9 to Mach 1.5) and a 7\% decrease in turn rate at Mach 1.2 as a result of the $250 \mathrm{lb}$ of additional dry weight. A Mach 2.0 fixed geometry intake with an additional compression ramp intake (additional shocks) was also considered, but discarded for similar reasons (12\% acceleration time penalty, $7 \%$ decrease in turn rate at Mach 1.2 and $250 \mathrm{lb}$ of additional dry weight). Incidentally, such an intake was later designed for the F-16/79, powered by the GE J79 engine, but, although it had a $20 \%$ higher total pressure recovery and 68\% lower spillage drag at Mach 2.0 [12], the resulting weight penalty turned out to be one of the main reasons why the F-16/79 never went into service.

Giving due consideration to the tradeoff with overall airframe, drag is usually also part of the shock system structuring decisionmaking process. Even if, for a given design, an external compression intake gives better pressure recovery, a normal shock intake may have less drag on account of its generally smaller capture area.

The capture area and its complex influence on pressure recovery and drag is an issue with both supersonic and subsonic designs [13]. It usually arises when high performance is required at a wide range of airspeeds. If the intake has a large capture area, or, more to the point, a high capture area/throat area ratio, that is, it is optimized for low speeds, the excess airflow spilling around it at high speeds will separate and thus will contribute to the overall drag (spillage drag).

*The momentum loss due to the flow being spilled is balanced by the increased cowl thrust that comes from the accelerated flow around the lip and the cowl. 

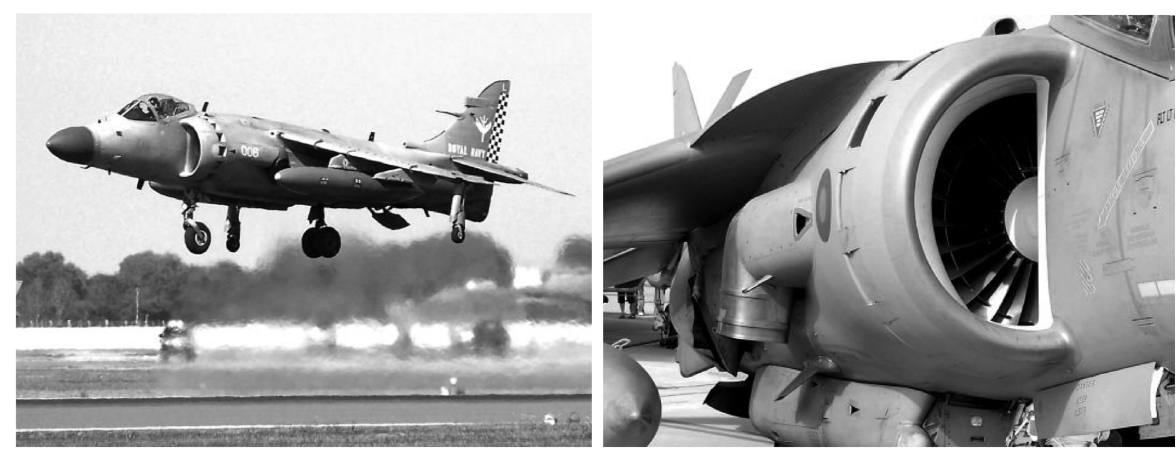

Fig. 8 Blow-in doors on the Harrier: fully open in the hover (Sea Harrier FA2, left) and partially closed (Harrier GR.9, right).

Equally, sizing the capture area for high speed operation will mean loss of performance at low speeds, due to insufficient air reaching the engine. This balancing act is often resolved at the expense of bringing additional complexity into the tradeoff calculation, generally in one of two ways.

The first solution is the use of intermittently operating auxiliary intakes. These typically open at low speeds, thus effectively increasing the capture area, and close when they are not needed, and they usually take the form of blow-in doors. Early transport aircraft featured these, for example, the Boeing 707, some Boeing 737-200s and early Boeing 747s, as well as the Lockheed C-141 Starlifter transporter, the Boeing B-52 bomber (Fig. 7), the Panavia Tornado strike/fighter aircraft, etc. Figure $\underline{8}$ illustrates the operation of the intake of the Harrier GR.9 and its blow-in doors, required in particular in the hover, when the speed of the freestream airflow is zero, yet a great deal of thrust is required. Another example is the MiG-29 (Fig. 9): the maximum capacity of its blow-in doors is high enough to allow the pilot to taxi and take off with the main intake sealed off by a door, preventing foreign object damage when operating on semiprepared surfaces.

The second possible route is to vary the geometry of the inlet according to flight conditions, that is, depending on the airflow available. The potential of variable intake geometry lies not only in variable capture area, but also in allowing it to adapt to variations in the angle of attack of the flow (as on the F-15 or the Eurofighter Typhoon), vary the thickness of the lips (as on the P1127 mentioned earlier), change the position of the shocks (e.g., translating central spike designs), or vary the boundary layer bleeding mechanism (more on that later). The reader interested in the evolution of complexity in intake design in the 1960s and 1970s will find the discussion by Surber and Goldsmith [14] enlightening.

Recently, some designs have been driven away from the variable geometry concept by cost and project risk considerations (see, for example, Philhower's comments [15] on the development of the Joint Strike Fighter air induction system: a cost-conscious fixed geometry, normal shock intake). As far as the future is concerned, smart structures may hold the key to this particular tradeoff: newly developed smart materials may allow geometry variations with a minimum number of additional moving parts. Promising work in this direction has recently been carried out within the Smart Aircraft and Marine Project System Demonstration (SAMPSON) project [16].

We note here that the drag contribution of the intake in the preceding discussion refers to operational drag, that is, when the engine is running. However, when one factors safety into the equation, the engine-out drag must also be considered, both when the engine is windmilling and, in the worst case scenario, when the fan is not rotating at all [17]. In other words, a certain capture area and forward-nacelle size may hit the optimum operational drag vs pressure recovery tradeoff, but may reduce the aircraft's glide lift to drag ratio by an unacceptable margin or it may result in an excessive yawing moment when the critical engine is inoperable.

On many installations, particularly on military aircraft, an element of the air induction system as important as the inlet itself is, of course, the duct. For high, uniform pressure recovery this should be as close to straight as possible, as any curvature may lead to separation and thus loss of total pressure. Bends, usually S-bends, are, however,

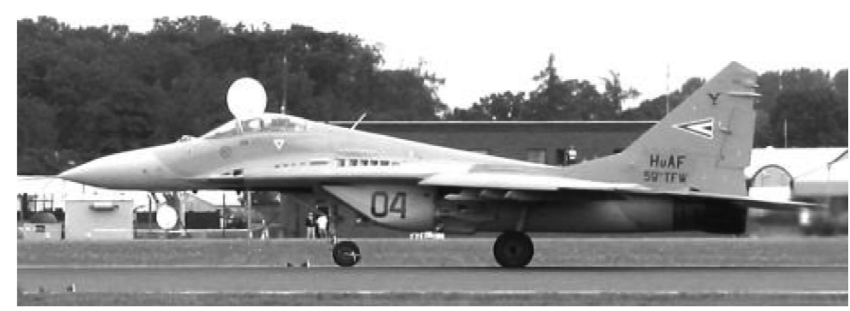

Fig. 9 Blow-in louvres on the MiG-29.

inevitable on many designs. Special care must be taken in extreme cases, where highly offset intakes are demanded by layout and center of gravity constraints (such as on the Harrier; see Fig. $\underline{8}$ ) or radar susceptibility requirements (line-of-sight shielding of the engine can be observed, for example, on many modern unmanned air vehicle designs). Computational studies have allowed careful shaping of Sducts in recent years; the reader interested in charting recent progress in this area may want to review, for example, the work by Jenkins and Loeffler [18] or the more recent studies of Knight and coworkers $[19,20]$. The great challenge here lies in balancing the high computational expense of analysis codes that are accurate enough to predict such pressure losses against the need for analyzing a large number of candidate designs for a meaningful optimization study.

We have concentrated throughout this section on integrated intake installations, because these generally pose more difficulty when it comes to designing for a good pressure recovery vs drag balance. The design of podded installations, as featured by most transport aircraft, have slightly different challenges. In a 1976 article Haines [22] pleaded against the standard practice of designing a good intake and a nacelle in isolation and then attaching it to the wing or the fuselage, as dictated by structural considerations. Instead, he argues, the wingfuselage-nacelle-pylon assembly must be designed as a whole. Design practice has begun to follow this principle; an early NavierStokes flow-simulation-aided design example can be found in the work of Eleshaky and Baysal [23], who performed a gradient-based design search on a simple nacelle/wing model (the latter represented by a flat plate).

\section{B. Forebody Boundary Layer}

The ingestion of the low-energy forward-fuselage boundary layer can have an unfavorable effect on the pressure recovery of the intake, both in terms of its average magnitude and its distortion. As we have seen earlier, this was evident already in the early 1950s [4] and it became an increasing concern as the majority of designs started featuring intakes that inevitably captured a streamtube that had been in contact with the fuselage (i.e., they were not of the nose- or wingmounted pitot variety). We have discussed the drag vs pressure

${ }^{\S}$ So-called multilevel design techniques have been found by some to be an effective compromise [21]. These involve running the bulk of the optimization study on a low cost, low-fidelity physics-based prediction, occasionally validated/calibrated by a high-fidelity (typically Reynoldsaveraged Navier-Stokes) solver. 


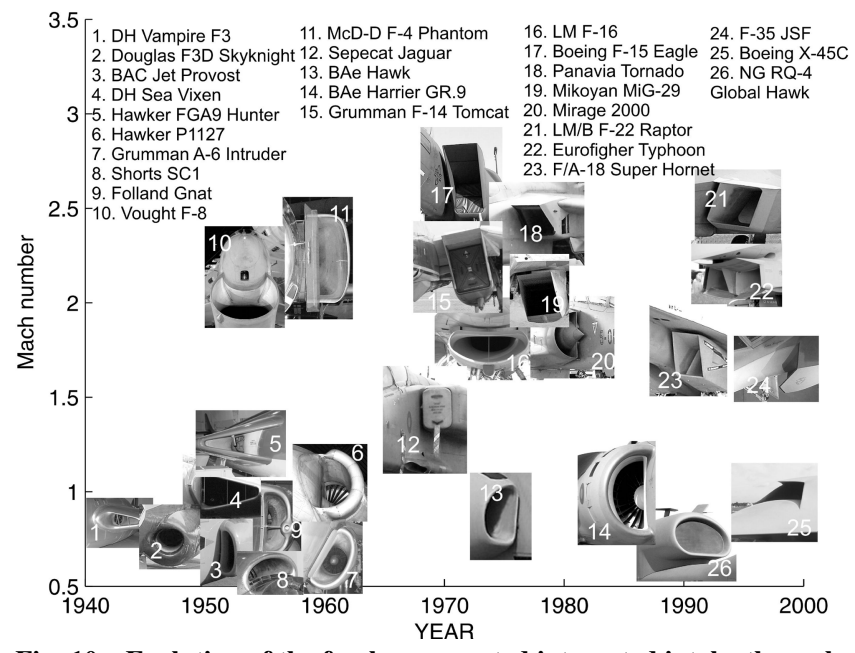

Fig. 10 Evolution of the fuselage-mounted integrated intake throughout the jet age, represented on a maximum Mach number vs year of first flight chart (the location of each image is approximate due to space constraints).

recovery tradeoff in the preceding section, and these are two of the main conflicting objectives appearing here as well, in a slightly different guise and in combination with the interrelated trio of cost, weight, and complexity.

The pressure losses and distortions caused by the ingested boundary layer increase with Mach number and, beyond approximately M0.6, some form of boundary layer treatment becomes necessary. This can be done by diverting it or by bleeding it out of the captured airstream, a process that inevitably incurs a drag penalty. A great variety of boundary layer diverter types have been developed over the decades; some of these are illustrated in Fig. 10 through a range of fuselage-mounted intake examples. The earliest method was to simply create a step just ahead of the intake, with a height approximately equal to the thickness of the boundary layer at that point along the fuselage (de Havilland Vampire F3), sometimes extending the outboard side of the step to create an additional barrier between the boundary layer and the clean airstream (de Havilland Sea Vixen; see both aircraft in Fig. 4).

The dominant design solution of the 1950s was to split the intake into a small, boundary layer subintake and a main intake: the flow from the former, of course, had to be channeled away, usually to an exhaust nozzle located further downstream. Examples shown in Fig. 10 are the BAC Jet Provost (3), the Hawker FGA9 Hunter (5), the Folland Gnat (9), and the Shorts SC1 (8). The splitter plate diverter, as a preferred solution, marked the beginning of the 1960s, some of the most prominent examples being the McDonnel-Douglas F-4 Phantom (11), the Grumman A-6 Intruder (7), and the Hawker P1127 experimental STOVL aircraft (6). The latter featured a splitter plate with a curved leading edge, the highly swept sides of which were designed to generate a boundary layer wake to be ingested by the engine, in an effort to reduce fuel consumption at the expense of high-speed thrust loss and some degree of distortion [7].

From the late 1960s onwards the leading school of thought has been to offset the intake, that is, to move the entire capture area sufficiently far off the fuselage to ensure that as little boundary layer air is ingested as possible. There is, of course, an aerodynamic tradeoff here. The larger the offset, the smaller is the ingested proportion of the boundary layer, but large offsets usually mean increased drag (on account of the increased frontal area) and an increased possibility of separation in the more convoluted duct (leading to fan face pressure distortions).

\footnotetext{
The drag-accounting of boundary layer diverters must be done with extra care. Bore [7] remarks that it became clear during the development of the Hawker P $11 \overline{2} 7$ that the drag of everything that reduces the total pressure of the intake flow (such as a plate-type diverter upstream of the intake) should only be accounted for in that total-pressure loss and should not be included in the overall drag of the rest of the aircraft.
}

If this offsetting of the inlet is not a feasible solution, for example, due to space constraints (as on the Harrier, where the duct has to be very short and therefore any offset has to be kept to a minimum), the standard alternative is to bleed the boundary layer out of the airstream being captured by the engine. Sophisticated bleed systems are also required on supersonic designs, where the interaction between the shock(s) and the boundary layer (formed on the fuselage and on the shock-generating surfaces of the intake) must be carefully controlled. The key tradeoff here is between the weight, cost, and complexity of the bleeding mechanism and the aerodynamic efficiency and stability of the shock system.

An example of the high complexity end of this tradeoff is the variable capture area design of the F-15 Eagle [24] (17), where sideplates, the ramps, and a throat slot share the boundary layer bleed in a $15-15-70 \%$ proportion, regulated by a sophisticated electronic control system [25]. The bleed from each source is exhausted through different sets of louvres located on the top of the intake. In some cases it may be possible to compensate, to some extent, for the additional drag generated by the bleed ducting by using the boundary layer bleed for engine cooling [26], though experience from the development of the F-111A, where this was attempted, shows that the tortuous flowpath of the cooling air can reduce its flow speed to such an extent that much of the boundary layer air will spill into the intake anyway [14].

The opposite, low-cost end of the scale would, of course, be represented by designs with no boundary layer diverters or bleeds at all. This is, perhaps, a good time to recall once again the 1951 NACA flush intake study by Sacks and Spreiter [4]. Looking at the behavior of the boundary layer along the approach ramp of the intake they emphasized the importance of the geometry of the ramp. On a conventional, scoop-type installation, the upstream parts of the fuselage surface take, to some extent, the role of the approach ramp and thus, it can be seen intuitively that careful shaping of the fuselage in that area can be beneficial from the boundary layer diversion perspective. Nevertheless, it was not until the late 1990s that all the required technologies (most importantly high-fidelity unsteady flow simulations and stereolitography) were in place for an in-depth study into the possibility of forward-fuselage shaping. Such a diverterless boundary layer treatment system was first employed by Lockheed Martin on an experimental F-16 Block 30 variant as a preliminary study before the design of their first production aircraft to feature this technology: the F-35 Joint Strike Fighter (Lightning II). The relevant patents $[27,28]$ were granted in 1998. The intake weight savings achieved by eliminating the need for a diverter are reported to be as high as 30\% [29]. It is also worth noting that the Joint Strike Fighter competition's other entry, the Boeing X-32 also had a diverterless boundary layer handling system, perhaps further underscoring the future potential of this technology (in fact, there are already notable efforts to develop diverterless top-surface intakes for blended wingbody aircraft, where the alternative would be to install the engines away from the top surface, on top of costly and heavy pylons).

\section{Inlet Flow Distortion}

We have hinted already that the ideal intake delivers a totalpressure field at the engine face that is not only high in terms of its average value, but is also uniform. Although a low average (low pressure recovery) can reduce thrust and often efficiency, distortions in the pressure field can lead to fan and compressor blade fatigue, can reduce the surge margin of highly loaded sections of the compressor, and often also increase noise. This double-objective design problem often comes with the added twist of the robustness issue. It was already known in the 1950 s that designs with very high-average pressure recovery values can be sensitive to off-design operation and, hence, may give higher distortion levels over a range of operation than a lower recovery inlet [30].

Although some of the potential effects of distorted pressure fields were known from the beginning of the jet age, the importance of unsteady distortions was only recognized in the 1960s [31]. One of the research strands that focused minds in that period on the problem of distortion was the development of vertical takeoff/landing 

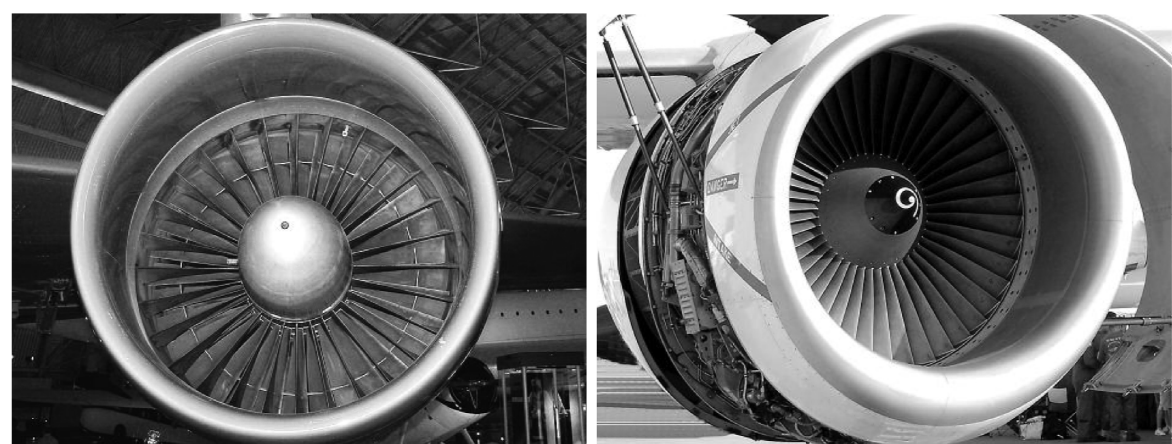

Fig. 11 Almost identical airframes, different engines, over three decades of intake design evolution: Boeing Dash-80 (left) and its much younger derivative, the E6-B Mercury (right).

concepts [32]. Turning the flow by $90 \mathrm{deg}$ (for a vertical lifting engine) inevitably led to separation in the duct, causing considerable engine face pressure distortions; eventually, on designs such as the Hawker prototypes preceding the Harrier, the problem was circumvented by passing the role of turning the flow to the nozzle.*** Nonetheless, Williams and Yost [33] reported in 1973 a $7 \%$ pressure loss on lift/propulsion turbofans due to static distortion and dynamic distortion reducing engine surge margin 1.5-3 times compared to those associated with steady-state distortion. Somewhat ironically, the design challenges of the Harrier's replacement, the F-35 Joint Strike Fighter (24), are similar: the lift fan has to cope with the distortions caused by a $250 \mathrm{kt}$ airflow perpendicular to its axis of rotation (during the transition between hover and horizontal flight).

A typical tradeoff encountered in designing for minimum distortion is that between the drivers dictating the shape of the intake lip. Flow over a very blunt lip will not separate (and thus cause distortion) even at relatively high angle-of-attack flight, strong crosswinds, or sideslip. However, a thinner lip is preferable from the drag point of view (especially in cruise conditions). Additional goals mixed into the design problem are manufacturing cost, weight (thick lips tend to be heavier and more expensive), and deicing and fire extinguishing system design (the latter two tipping the balance in favor of thicker nacelles that offer more space inside). Figure 11 illustrates the design impact of how the balance between these competing drivers has shifted over three decades: the E6-B Mercury (shown on the right) is essentially based on the same airframe as the Dash-80 (left of Fig. 11), designed over 30 years earlier, yet the shapes of the intakes are quite different: whereas the Dash-80 nacelles featured constant thickness, circular, slim lips, the shape of the lip on the E6-B nacelle is sligthly elongated, thicker at the bottom to prevent separation at high angles of attack, while also featuring a greater average thickness than those on the Dash-80.

Like with many low/high-speed performance tradeoffs, there have been attempts to solve the lip thickness problem through variable geometry designs. A notable example is the VTOL Hawker P1127 (precursor of the Harrier), where the need for full throttle operation at zero airspeed (hover) and good high-speed performance placed special emphasis on this tradeoff. The solution was to fit the intakes of the P1127 with generously shaped inflatable rubber leading edges for low-speed operations: these were then sucked down in high speed flight. However, high local Mach numbers were observed on the outside of the lips at low altitudes, which led to cases of ripple and rubber tearing [7].

To date, there is still no silver bullet solution to this problem, though, writing in 2000, Lord et al. [34] predicted thinner (cruiseoptimized) nacelles for the future, fitted with a separation control system, which could be engaged in takeoff, crosswind, and high angle-of-attack conditions; more on such systems shortly.

Another typical tradeoff relates to the length of the diffuser. The longer the intake and its duct, the greater the settling length will be

\footnotetext{
**This was still not a panacea for the intake designers, because the Harrier intake duct had to be offset over a very short longitudinal distance to create space for the turning nozzle, thus leading to the separation associated with highly curved ducts
}

over which pressure distortions can even out; of course, a weight and cost penalty has to be paid for the extra length. The example of the Lockheed C-141 Starlifter provides an indication of the weight sensitivity to settling length. By having virtually no duct at all (see Fig. 12), the payload capacity of the aircraft could be increased by $4000 \overline{\mathrm{lb}}$ over a $4000 \mathrm{~nm}$ mission. However, as had been expected, some separation inside the lip was observed in the $V=0$ to $V_{\text {liftoff }}$ speed range and, as Cleveland and Gilson [35] report, the resulting pressure distortion excited the blading in a way that could cause fatigue. Nonetheless, no performance penalty was noticed. It is worth mentioning here that in the decades passed since the design of the $\mathrm{C}$ 141 , another constraint has gained importance, which tends to drive up duct lengths on podded installations: the need for fan noise reduction (more on that shortly).

As with many of the other design drivers and constraints discussed here, design for low pressure distortion was given a boost in the 1990 s by the advent of high-performance computers capable of highfidelity unsteady flow simulations. Some of the early efforts here include the distortion modeling of highly offset diffuser flows by Jenkins and Loeffler [18] and the use of computer simulations to predict the effect of vortex generators on inlet flow distortion [36]. Such studies are most valuable when validated and calibrated against flight test data, as they can reveal the limits to which the simulations can be trusted. For example, reporting in 1996 on the flight test results on the F/A-18 intake, Smith et al. [37] pointed out that certain instances of high angle-of-attack separation observed in flight testing were missed by their steady Navier-Stokes simulations; nonetheless, for most flow conditions the numerical results were within the excursion range of the unsteady experimental data.

Experimental studies also benefited from the increases in computing power seen in recent times. This is mainly due to the high measuring and data processing demands of unsteady pressure distortion monitoring: perhaps one of the main reasons why it took the design community a relatively long time to understand its true importance, including its effects on engine performance and operation $[\underline{24}, \underline{38}]$.

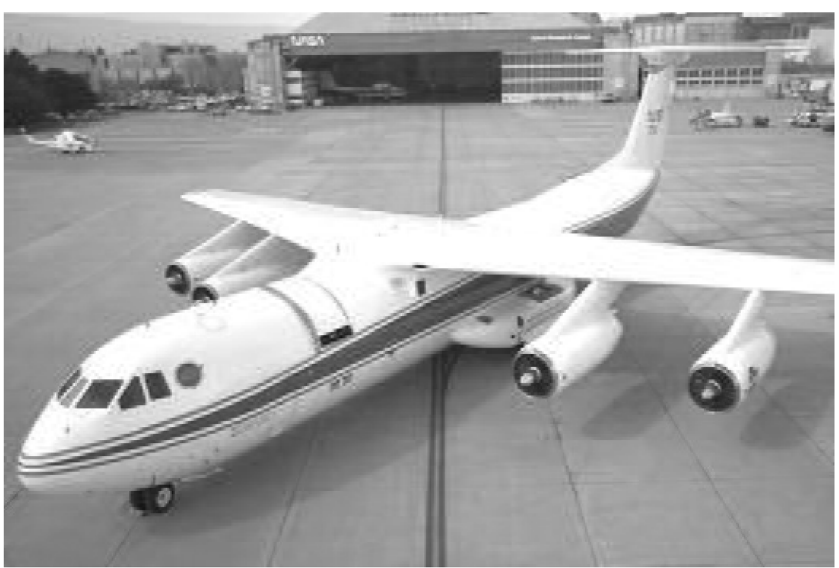

Fig. 12 Ductless intakes on the Lockheed C-141 Starlifter (NASA image). 
Much research has focused over the last decades on the use of active flow control as a means of preventing separation, for example, by using tangential blowing through slots near the lip or in the duct [39] or by using directed synthetic jets, which remove low momentum air from the surface and, on their opposite stroke, blow it back to reenergize the boundary layer [34]. There is, of course, a cost, complexity and cruise drag penalty associated with such systems, as well as some loss of thrust on those systems that require engine bleed air. A recent technology that shows promise in terms of having a minimal impact on cruise drag is the use of micro-electrical mechanical system (MEMS) devices for flow control [40].

In general, the aim of such systems is to relax the effect of crosswind and/or high angle-of-attack constraints that demand thick, rounded intake lips and therefore are in opposition with the drag, cost, and weight drivers. They can also be beneficial in the case of blended wing-body designs, where, as we mentioned in the preceding section, considerable weight, cost, drag, and signature gains can be made by burying the engine into the top surface of the aircraft (as opposed to keeping it in the clean, high-energy airflow, on top of a pylon), if the inherent pressure distortion (and mean pressure recovery) penalties can be minimized $[\underline{41}, \underline{42}]$.

\section{Vying for Space: Positioning of Integrated Intakes}

The three designs shown in Fig. 1 are representative of the earliest integrated installations. Placing the inlet in the nose had the advantage of it capturing clean, freestream air, but it had the disadvantage of occupying too much precious fuselage real estate. It also often required a complex duct design to get the airflow around (MiG-15, Gloster E28/39) or under (F-86 Sabre) the cockpit, a problem often further aggravated by the complex bifurcated front casings of early centrifugal compressor gas turbines [43] and the need to also accommodate some of the fuel tanks in that area. The need to carry radars constituted the final blow to the nose intake. Apart from some early small radars that could fit into the bullet centerbody of a supersonic intake (as in the case of the MiG-21, Fig. 5), the only solution was to move the intake out of the fuselage, thus freeing up space in the nose. This was the outcome of the redesign of the F-86 Sabre (Fig. 1, right), the later interceptor version of which had the intake moved into a ventral position, as shown in Fig. 13 .

Although ventral intakes, such as that seen on the F-86D, were (and still are) considered a favorable solution compared to dorsal designs, due to their better performance at high angles of attack, when the latter criterion was less important, top-mounted installations were occasionally considered. Their attraction was minimal interference with the weaponry, an unobstructed lower fuselage for stores integration as well as a reduced radar cross section. A rare example of such an aircraft that made it to the prototype stage (though not into service) was the 1956 North American F-107A (Fig. 14).

As Fig. 10 illustrates, the types that dominated the following decades were the ventral and the scoop-type side intake. Although side intakes have the advantage of leaving the underside of the

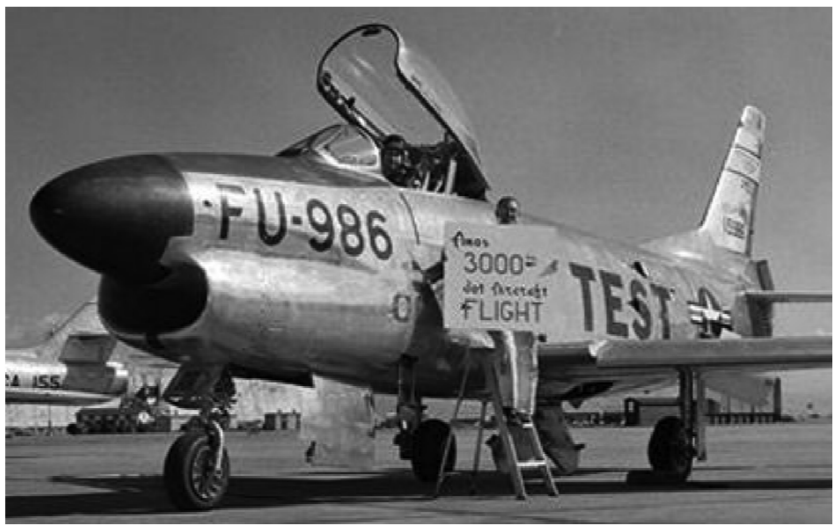

Fig. 13 North American F-86D with ventral intake (NASA image).

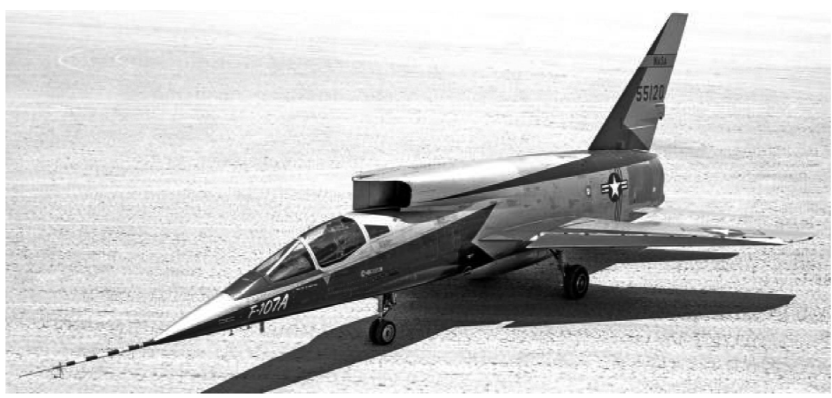

Fig. 14 North American F-107A with dorsal intake (NASA image).

fuselage free and unobstructed, particularly important for strike aircraft carrying a large range of weapons, mounting the intake on the underside, aft of the nose, has the attraction of using the bottom surface of the front fuselage to preturn the flow in high angle-ofattack flight and therefore reducing the risk of separation on the inlet lip (a good example is the F-16). A compromise solution is to place the intakes and their ducts on the lower corners of the fuselage; a recent example is the Dassault Rafale (Fig. 15).

In the background of the domination of side-mounted and ventral intakes (as well as their hybrids), something of a revival of the dorsal intake has been seen in recent years (one of the early studies marking the beginning of this rebirth is the 1980 paper by Williams and Hunt [44]). This is primarily driven by susceptibility considerations; we shall discuss these later.

\section{E. Design of Transport Aircraft Inlets for Reduced Noise}

The rapid growth of jet travel in the 1960s led to the emergence of what was to become one of the most active strands of transport aircraft jet intake research over the following decades, up to the present day: the science and technology of noise reduction. As we shall see in the following, although many different noise supression concepts have been considered over the years, the dominant technology is and has been that of absorptive linings. These can be found as early as the mid-1960s, on the JT8D-1 turbofan-powered Boeing 727. It is worth noting that the tail-mounted engines of the 727 had the beneficial effect of the intakes being shielded from the ground from certain angles. Although this reduced the duration of the exposure to noise, it had less of an effect on its peak; the lining was therefore designed to alleviate the latter, in particular at the fan speed corresponding to approach thrust. The resonator lining featured 1/8-in. holes, 24 per square inch [45]. The first formal noise regulations (FAR 36) were issued in $\overline{19} 69$ and, in spite of having entered service before these and therefore not required to comply, the 727 later still received a further enhanced attenuation system (727300). Nonetheless, as Phil Condit (subsequently to become Chairman and CEO of The Boeing Company) noted later [46], due to uncertainty over what the 1970 s noise regulations were to demand, the airlines chose not to risk buying the 727-300.

May 1967 saw the launch of the ambitious "Treated-Nacelle Program," a collaborative effort between NASA, McDonnellDouglas, and The Boeing Company. The aim was to develop

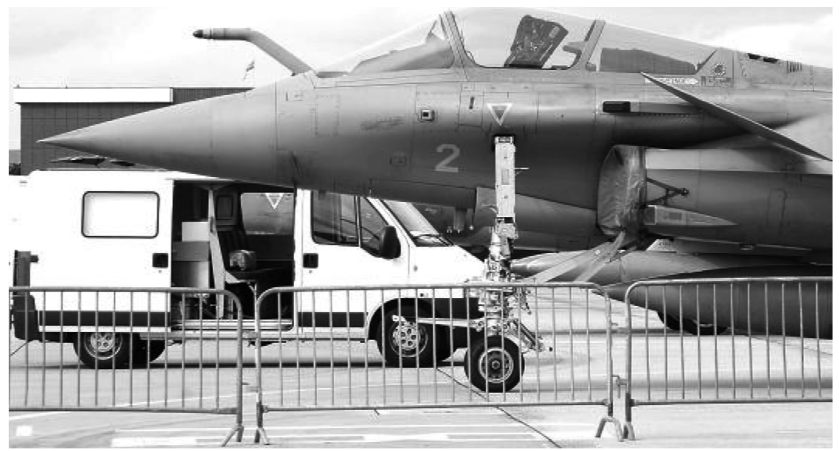

Fig. 15 Rafale intake installation: a compromise between ventral and side-mounting. 


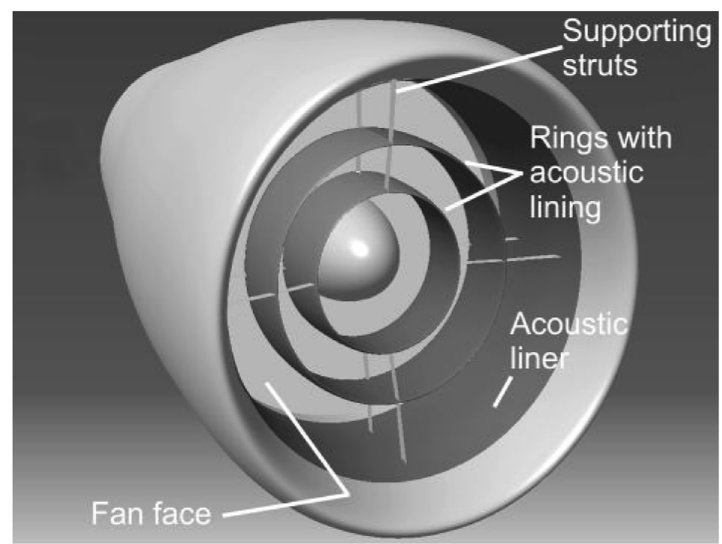

Fig. 16 Intake noise suppression rings.

technologies to suppress noise during landing; it was thought that a $7-10 \mathrm{PNdB}$ reduction could be achieved by careful design of the inlet of large subsonic aircraft. One of the technologies considered was the sectioning of the intake by two concentric rings (as shown in Fig. 16), covered with absorptive lining. It was found that its impact on other intake design drivers was considerable. Most importantly, the additional weight was around $150 \mathrm{lb}$ and specific fuel consumption increased by $0.6 \%$. The direct operating cost was expected to increase by $1.2 \%$. Further technologies examined by the program included an intake design that would create a region of accelerated flow to oppose the forward propagation of noise within the inlet (sonic throat inlet) and a variable cowl and centerbody geometry. The greatest drawback of the latter was found to be an estimated increase in direct operating cost of around 7-10\% [47].

Argyris, in his 1969 Lanchester memorial lecture [48], drew attention to another issue associated with the double ring design: that of performance robustness. He argued that "extremely tight tolerances must be held on the various contours," because any small deviation in the vane shapes can give rise to significant changes in the inlet pressure distributions. He backed up this and other observations on this novel noise attenuation technology with one of the first examples of the use of digital computers in intake design: a set of potential flow analysis calculations on a model of the bullet (at the center of the intake) and the cylindrical guide vanes. Liners continued to be the cornerstone of noise attenuation technology throughout the 1970 s, especially with the introduction of weightsaving composite materials (the first commercial composite nacelle was produced in the mid-1970s by Rohr, Inc., now part of Goodrich [49]). Dawson and Sills in their rather optimistically titled 1972 study "An End to Aircraft Noise?" [50] estimated the impact of liners on the noise levels of the RB211 at about $10 \mathrm{~dB}$ at $2 \mathrm{kHz}, 4 \mathrm{~dB}$ at $4 \mathrm{kHz}$, and $3 \mathrm{~dB}$ at $5 \mathrm{kHz}$.

In a 1973 paper Hodge et al. [51] urged the scientific community to follow up the promising results obtained with sound-absorbing

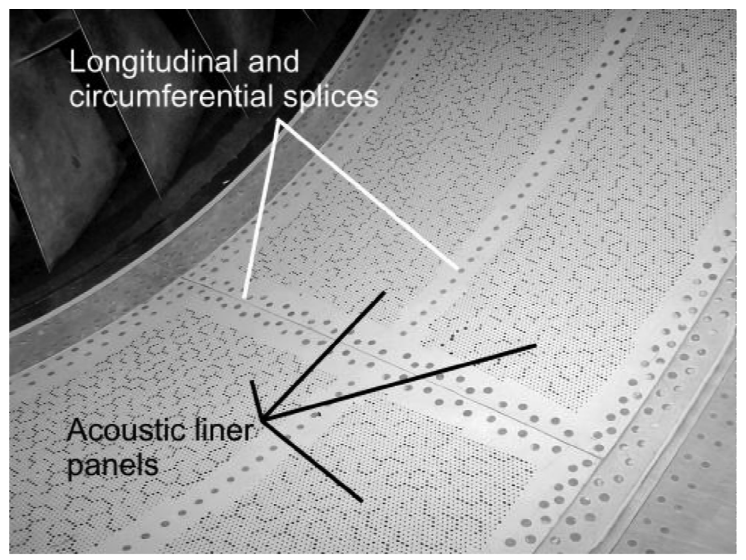

Fig. 17 Spliced inlet liner on the Rolls-Royce RB211-22B. linings by further research and development, aimed at extending the technology to double-layer linings, while minimizing "the significant inlet recovery and weight penalties associated with the installation of acoustic treatment. There are no unresolvable design problems associated with acoustic treatment," they went on to say, "however, the designer must carefully address the need for increased anti-icing, structural integration at minimum weight penalty, fan blade access, bird strike resistance, foreign object damage, maintainability and reliability." The lined area and, consequently, the length of the diffuser are the drivers that pull against most of the criteria listed earlier (with the notable exception of pressure distortion, which, as we have seen, is also improved by an increased settling length). As technological advances have allowed the relaxation of some of these constraints over the last decades, the duct lengths and liner surfaces have increased steadily from hardly anything (C-141 Starlifter, Fig. 12) to as much as $42.3 \mathrm{ft}^{2}$ on the PW4084-powered Boeing 777-200 and, only three years later, to $67.6 \mathrm{ft}^{2}$ on the PW4098-powered 777-300.ti

An additional design decision that has usually been associated with the liners relates to their splicing. The splices, as shown in Fig. 17, are solid sections of the inside of the inlet, their width and spacing being dictated by structural and manufacturing considerations. The circumferential variations in acoustic properties caused by these hard-walled strips can significantly alter the modal spectrum of the duct [52] and therefore recent research has focused on the potential advantages of reducing the widths and increasing the spacing of the splices [53], possibly incurring a manufacturing cost or weight penalty. In fact, at the time of writing, a one-piece acoustic liner is being tested as part of the General Electric GEnx engine development program and is showing significant noise benefits [54].

Another active area of research focuses on finding the optimum parameters of the liner itself, including thickness, hole diameter, and percent open area [55]. Finally, potential improvements being considered are applying blowing or suction through the liner or increasing its temperature [56]; the energy expense and additional complexity and cost involved are not clear at present.

In recent years developments in computational fluid dynamics and aeroacoustics [57-59] have allowed researchers to examine the impact of large-scale intake geometry changes on overall engine noise. One of the most notable directions being considered is that of intakes with negative scarf angles (as shown in Fig. 18), which radiate much of the noise upwards, away from the community. This is a concept that has been around since the 1980s, but its aerodynamic and cost implications have been thought to outweigh any acoustical benefits [60]. Recently, the Advanced Subsonic Technology Noise Reduction Program (funded by NASA and the FAA) and the SILENCE(R) project [61] (funded by the European Community, Rolls-Royce, Airbus, and Snecma) investigated the balance between the noise reduction potential and the detrimental effects of negative scarf angles. The latter study has found that negative scarfing causes the bulk airflow direction to move significantly upwards, which causes lip overspeeds on the upper half of the intake for many flow conditions, leading to potential shock loss and lip separation (the reader will recall from an earlier section that this is the same phenomenon that plagues swept intakes!). Similarly, NASA scientists have found that in stationary or low-speed conditions, airflow into the engine accelerates around the lip of the negatively scarfed inlet and pockets of turbulence that cause noise and vibration can be ingested [62]; their efforts to reduce these detrimental effects by active flow control were unsuccessful. Although all of these studies have found acoustic benefits in negatively scarfed designs, the jury is still out on their feasibility, when all other operational constraints and criteria are considered.

\section{F. Designing for Combat Survivability}

There are two facets to survivability: susceptibility, that is, the probability of being detected and the probability of being hit by a

\footnotetext{
†Data available online at http://www.icao.int/icao/en/ro/nacc/acilac/
} 19_goetz_boeing_aviaenvir.pdf. 


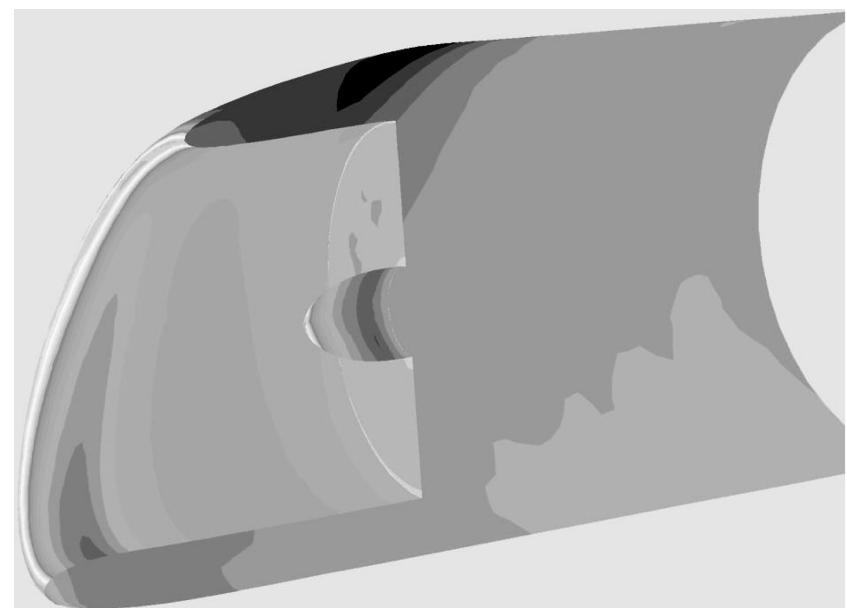

Fig. 18 Contours of total pressure on the surface of a negatively scarfed nacelle.

given threat, and vulnerability, which characterizes the response of the aircraft given a hit. The intake designer has the means to influence both positively, though often only by making sacrifices on other design drivers. Susceptibility depends on the signatures of the aircraft. This can mean heat-, radar-, visual- or noise-signature, though most effort is usually focused on minimizing the radar cross section (RCS) impact of the intake shape [63] by aligning the inlet lips with the wing leading edge (Boeing X-45), placing the intake on top of the fuselage (F107, Northrop-Grumman X-47 and RQ-4A Global Hawk, Boeing X-45, etc.), covering the intake face with a grating (Lockheed F-117 Nighthawk) or the engine face with blocker vanes (Boeing F/A-18E/F Super Hornet), etc. Although most of these measures involve penalties in terms of pressure recovery (mean and distortion), drag, weight, cost, etc.,粆 perhaps the most challenging design task is the requirement to offset the engine from the intake face to the extent that the rotating fan blades are shielded from any radar. This usually leads to the need for highly convoluted intake ducts, which are notorious for generating a highly distorted pressure field on the engine face (due to the flow separating at the bends).

The conclusions of the Vietnam War and the Yom Kippur War prompted the first serious studies on vulnerability considerations involved in intake design. The reader interested in this aspect may find Throndson's [63] reflections revealing. Designing for low vulnerability takes us back to the space and packaging issues discussed earlier. The most important consideration here is the location of the fuel tank in relation to the intake duct, because, if a projectile pierces the duct/tank wall, fuel may be sucked into the intake resulting in the loss of the aircraft.

\section{G. Ground Crew Safety, Surface Clearance, and Foreign Object Damage}

The first documented example of a crew member being sucked into an inlet is almost as old as jet aviation itself. According to Moult [43], in the spring of 1941 a Gloster E28/39's engine was being tested when "... .Michael Daunt, the test pilot, was strolling around dressed in a rather floppy coat. Suddenly he appeared to spin on his heels, lost his balance and took a dive into the intake of the engine." (He was unharmed, apart from a few bruises.) There have been a number of such accidents since then, though not numerous enough to warrant the installation of permanent protective grills to cover the intakes. Such a design feature would involve significant weight and cost penalties, as well as potential pressure recovery deterioration and severe distortion caused by the flow separating over the grill, particularly at high angles of attack. Nonetheless, flow straighteners

\footnotetext{
\#An additional burden on the inlet designer is that the flow itself arriving at the inlet may already be affected by the strong vortices generated by an angular forward fuselage shaped for low observability [64].
}

and swirl-reduction devices seen on some designs have the serendipitous effect of improving ground crew safety.

A similar risk that sometimes can be designed against is the ingestion of foreign objects. In extreme conditions (for example, taking off from semiprepared strips) a door might be necessary that seals the (main) intake while taxiing. We have seen this feature earlier on the MiG-29 (see Fig. 9), where a set of top-mounted louvres supply the necessary air while the foreign object door is closed. Short of such complex measures, placing the intake ahead of the nose gear reduces the risk of foreign objects being picked up and sucked into the intake (as, for example, on the F-16). The issue of robustness also arises here; it is good design practice to avoid intake shapes that provide high performance in nominal circumstances, but where relatively small amounts of foreign object damage can cause their performance to deteriorate significantly. As we hinted earlier, this was one of the reasons why the double-ring noise attenuation method (see Fig. 16) never had any serious success: small changes in the vane shapes could have easily led to sharp drops in performance [48].

Another aspect of keeping the captured airflow free of contamination is to avoid the ingestion of smoke and hot gases. The typical source of the former is the nose-mounted gun of the aircraft: the standard solution is to position the guns in such a way that the forward fuselage shields the intake from them. An extreme example of this is the Rutan 151 ARES, with its single engine and single intake mounted on the port side, while the massive $25 \mathrm{~mm}$ rotary barreled cannon occupies roughly the equivalent fuselage area on the starboard side; thus, the entire forward fuselage acts as a gun smoke shield.

A more difficult problem is that of the ingestion of hot gases, a problem that occurs mostly during thrust reverser operation and on short takeoff and vertical landing (STOVL) designs. Again, possible solutions involve the design of the entire airframe rather than just the intake: shields can be designed to favorably redirect the fountain flow that impinges on the aircraft, minimizing the amount of hot gas projected ahead of the aircraft, locating the intakes as high as possible, etc.; the interested reader will find a more detailed analysis of this problem in an article by Kuhn [65]. Fundamentally, the problem lies in the nature of the fountain flow impinging on the ground; it is extremely complex to model computationally and experiments are very costly [Behrouzi and McGuirk [66] recently used particle image velocimetry (PIV) in a special STOVL study water tunnel; see also the work by Saddington and Knowles [67], looking at the effect of the intake flow on the lift generated by the wing].

Finally, a note on surface clearance considerations and the extent to which they can influence intake design. Figure 19 illustrates this via two very different examples. The first is the rather unique Saunders Roe S.R.1 flying boat, with a sharply rising, long intake duct: an aerodynamically unfavourable solution, dictated by the requirement to minimize water ingestion on takeoff and landing, while placing the engines close to the bottom of the hull for better stability. The second example illustrates the use of intakes with noncircular lips: again, an aerodynamic compromise made necessary by ground clearance considerations. Such inlet lips also raise manufacturing problems, particularly when composite materials are used [68].

\section{H. Structural Design Drivers}

The loads driving the structural design of most intakes and their ducts are those associated with hammershocks, that is, strong shock waves traveling upstream through the duct as a result of an engine surge. Particular care must be taken with delicate attached parts, such as ramp linkages and auxiliary intake doors; for example, in the case of the Panavia Tornado, hammershock considerations led to the fitting of large, faired dampers onto the spring-loaded auxiliary intake doors to avoid rapid and structurally damaging movement caused by a potential surge [69].

As with other unsteady phenomena, the mathematical, computational and experimental difficulties meant that as late as the 1970s, 

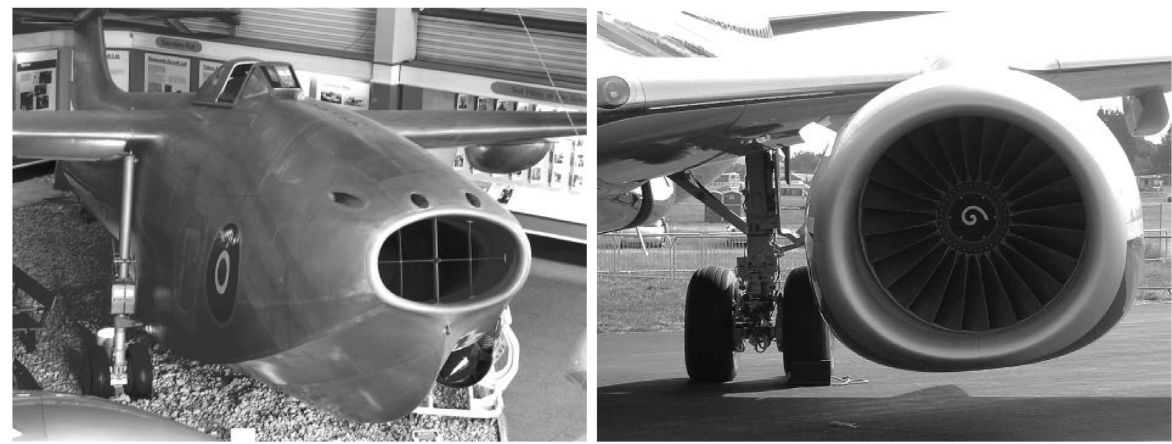

Fig. 19 Surface clearance considerations: the Saunders Roe S.R.1. flying boat and the Boeing 737-900.

design calculations were still largely based on what scarce test data were available from previous aircraft (see the 1975 review article by Young and Beaulieu [70]). For example, General Dynamics designed the F-16 intake duct in the early 1970s based on engine surge pressure data they had obtained from F-111 flight tests [71]. Although simulation, testing, and measurement capabilities were lacking, it was already clear then that the severity of the pressure transients was strongly related to the cross-sectional geometry variation of the duct, as well as the inlet boundary layer control provisions [70]. More recent studies now suggest that the inlet lip shape can also have an impact on the surge pressure loads [72].

The 1990s have brought two significant advances with the potential to enhance our understanding of the tradeoffs between shaping the intake duct for high pressure recovery and designing for minimum hammershock loads, that is, for low structural weight. First, computational techniques and high-performance computers are now available that bring effective hammershock analysis within reach. Although simulating $0.05 \mathrm{~s}$ of shock wave propagation time on a 3-D forebody and inlet model still took Ytterstrom and Axelson [73] 74 days of computing time in 1999 (using an inviscid flow model), Moore's law suggests that multidisciplinary design optimization (MDO) loops will, in the near future, be able to include surge analysis alongside the computation of more conventional aerodynamic objectives (see also the Euler simulation work on the F-22 Raptor by Goble et al. [74] and the recent NavierStokes analyses of Menzies et al. [72]). The second important step forward in recent years was the stochastic analysis of hammershocks. Although, traditionally, inlet ducts were simply designed for the worst-case scenario of engine surge, such violent transient phenomena are relatively rare. The Monte Carlo simulation work of Gridley et al. [75] is an example of design philosophy moving towards relaxing the hard constraint on surge tolerance and designing for an acceptable risk factor instead.

\section{Conclusions}

The design of any jet aircraft air intake is the result of a complicated balancing act between a number of (mostly conflicting) objectives. It is hoped that the preceding discussion will have given the reader a useful survey of where our understanding of the tradeoffs between these goals has come from and how it has evolved over the years.

The design drivers we have discussed do not tell the whole story. There are a number of other goals and constraints that often need to be considered but, as yet, our understanding of the related phenomena is not sufficient to link them to the design variables that describe the shape and the structure of the intake. Therefore, they are usually evaluated and verified once a preliminary design has been produced. Typically, the phenomena in question are difficult to model because of their highly time-dependent (unsteady) nature. Examples are the self-sustained oscillations encountered by supersonic inlets operating in the subcritical flow regime [76,77] ("inlet buzz"), the instability of the terminal shock in high-speed mixed compression inlets $[78,79]$ (inlet unstart), etc. Although there has been major progress in the numerical simulation of these phenomena, further increases in computing power will be needed before they will become part of the multidisciplinary design loops currently including calculations of pressure recovery, drag, steady distortion, etc.

Similarly, the increasing fidelity of computational mechanics tools is beginning to allow blade separation calculations that are fast enough for intake designers to be able to get a timely assessment of the impact of design changes on the intake's ability to contain such events.

It is therefore clear that multidisciplinary design optimization and the computational analysis that underpins it will be amongst the key technologies that will determine the understanding of intake design tradeoffs in the near future. As far as the actual goals are concerned, it is likely that life cycle cost, and, in the civil aviation industry, noise reduction will emerge as the leading drivers of the near future, with advances in manufacturing technologies, the use of smart materials, and a better understanding of the intricate relationships between constraints and performance metrics permitting continued increases in performance.

\section{Acknowledgments}

The author would like to thank Peter Curtis (BAE Systems), Richard Thorne (Rolls-Royce), and Andy Keane, James Scanlan, and Alexander Forrester (University of Southampton) for their invaluable comments on the manuscript of this article.

\section{References}

[1] Seddon, J., and Goldsmith, E. L., Intake Aerodynamics, Collins Professional and Technical Books, London, 1985.

[2] Chambers, J. R., Partners in Freedom-Contributions of the Langley Research Center to, U.S. Military Aircraft of the 1990s, Monographs in Aerospace History, SP-2000-4519, NASA, 2000.

[3] Geddes, J. P., "Boeing Sells a Thousand 727s-and Hopes to Sell Plenty More," Interavia, Aerospace World : Business and Technology, Vol. 28, No. 3, 1973, pp. 245-247.

[4] Sacks, A. H., and Spreiter, J. R., "Theoretical Investigation of Submerged Inlets at Low Speeds," NACA Technical Note 2323, 1951.

[5] Ward-Smith, A. J., "A Prediction Method for the Influence of a Turbulent Boundary Layer on the Efficiency of Submerged Intakes," The Aeronautical Journal, Vol. 77, Nov. 1973, pp. 570-574.

[6] Stewart Rolls, L., "A Flight Comparison of a Scoop Inlet and a Submerged Inlet at Transonic Speeds," NACA Research Memorandum A53A06, 1953

[7] Bore, C. L., "Intakes for Vertical Landing Aircraft," Practical Intake Aerodynamic Design, edited by E. L. Goldsmith and J. Seddon, Blackwell Scientific Publications, Oxford, 1993.

[8] Curtis, P., and Whitmore, I., "The Development of the Nimrod MRA.4 Intake," 7th CEAS European Propulsion Forum, Council of European Aerospace Studies, Pau, France, 1999, pp. 1-10.

[9] Whitford, R., Design for Air Combat, Jane's, London, 1987.

[10] Ran, H., and Mavris, D., "Preliminary Design of a 2D Supersonic Inlet to Maximize Total Pressure Recovery," AIAA Paper 2005-7357, Sept. 2005.

[11] Hawkins, J. E., "YF-16 Inlet Design and Performance," Journal of Aircraft, Vol. 13, No. 6, 1976, pp. 436-441.

[12] Hunter, L. G., and Cawthon, J. A., "Improved Supersonic Performance for the F-16 Inlet Modifiied for the J79 Engine," Journal of Propulsion and Power, Vol. 1, No. 1, 1985, pp. 50-57.

[13] Dobson, M. D., and Goldsmith, E. L., "External Drag of Fuselage Side 
Intakes," Journal of Aircraft, Vol. 9, No. 2, 1972, p. 121.

[14] Surber, L. E., and Goldsmith, E. L., "Intake/Airframe Integration for Combat Aircraft," Practical Intake Aerodynamic Design, edited by E. L. Goldsmith and J. Seddon, Blackwell Scientific Publications, Oxford, 1993.

[15] Philhower, J. S., "Development of a Highly Offset Induction System for a Supersonic STOVL Fighter," AIAA Paper 1998-3417, 1998.

[16] Pitt, D. M., Dunne, J. P., White, E. V., and Garcia, E., "SAMPSON Smart Inlet SMA Powered Adaptive Lip Design and Static Test," AIAA Paper 2001-1359, 2001.

[17] Mattingly, J. D., Elements of Gas Turbine Propulsion, McGraw-Hill, New York, 1996.

[18] Jenkins, R. C., and Loeffler, A. L., "Modeling of Subsonic Flow Through a Compact Offset Inlet Diffuser," AIAA Journal, Vol. 29, No. 3, 1991, pp. 401-408.

[19] Zhang, W. L., Knight, D., and Smith, D., "Automated Design of a Three-Dimensional Subsonic Diffuser," Journal of Propulsion and Power, Vol. 16, No. 6, 2000, pp. 1132-1140.

[20] Lefantzi, S., and Knight, D. D., "Automated Design Optimization of a Three-Dimensional S-Shaped Subsonic Diffuser," Journal of Propulsion and Power, Vol. 18, No. 4, 2002, p. 913.

[21] Zha, G.-C., Smith, D., Schwabacher, M., Rasheed, K., Gelsey, A., Knight, D., and Haas, M., "High-Performance Supersonic Missile Inlet Design Using Automated Optimization," Journal of Aircraft, Vol. 34, No. 6, 1997, pp. 697-705.

[22] Haines, A. B., “Aerodynamics," The Aeronautical Journal, Vol. 80, July 1976, pp. 277-293.

[23] Eleshaky, M. E., and Baysal, O., "Shape Optimizing Nacelle near FlatPlate Wing Using Multiblock Sensitivity Analysis," Journal of Aircraft, Vol. 35, No. 1, 1998, pp. 33-38.

[24] Imfield, W. F., "Development Program for the F-15 Inlet," Journal of Aircraft, Vol. 13, No. 4, 1976, p. 286.

[25] Scherz, C. J., and Williams, L. E., "Digital Computer Application in the F-15 Engine Air Inlet Control System," Journal of Guidance and Control, Vol. 1, No. 6, 1978, p. 420.

[26] Segal, C., "Aircraft Engine Bay Cooling and Ventilation: Design and Modeling," Journal of Aircraft, Vol. 34, No. 1, 1997, pp. 141-144.

[27] Hamstra, J. W., and Sylvester, T. G., "System and Method for Diverting Boundary Layer Air," U.S. Patent No. 5, 779, 189, granted 14 July 1998.

[28] Hamstra, J. W., McCallum, B. N., Sylvester, T. G., Denner, B. W., and Moorehouse, J. A., "Transition Shoulder System and Method for Diverting Boundary Layer Air," U.S. Patent No. 5, 749, 542, granted 12 May 1998.

[29] Hehs, E., "JSF Diverterless Supersonic Inlet," Code One Magazine, Vol. 15, No. 3, 2000.

[30] Ramachandra, S. M., Sudhakar, K., Perumal, P. V. K., and Jayashima, P., "Air-Inlet Engine Matching Problems Encountered in a Jet Trainer Re-Engining Program," Journal of Aircraft, Vol. 19, No. 8, 1982, pp. 609-614.

[31] Oates, G. C., "Inlets and Inlet/Engine Integration," Aircraft Propulsion Systems Technology and Design, edited by J. L. Younghans and D. L. Paul, AIAA Education Series, AIAA, Washington, DC, 1989, Chap. 4, pp. 241-298.

[32] Tyson, B. I., "Tests to Establish Flow Distortion Criteria for Lift Engines," Journal of Aircraft, Vol. 2, No. 5, 1965, pp. 411-417.

[33] Williams, D. D., and Yost, J. O., "Some Aspects of Inlet/Engine Flow Compatibility," The Aeronautical Journal, Vol. 77, Sept. 1973, pp. 483-492.

[34] Lord, W. K., MacMartin, D. G., and Tillman, T. G., "Flow Control Opportunities in Gas Turbine Engines," AIAA Paper 2000-2234, 2000, pp. 1-15.

[35] Cleveland, F. A., and Gilson, R. D., "Development Highlights of the C141 Starlifter," Journal of Aircraft, Vol. 2, No. 4, 1965, pp. 278-287.

[36] Anderson, B. H., and Levy, R., "A Design Strategy For the Use of Vortex Generators to Manage Inlet-Engine Distortion Using Computational Fluid Dynamics," AIAA Paper 1991-2474, 1991, p. 10.

[37] Smith, F. C., Podleski, S. D., Barankiewicz, W. S., and Zeleznik, S. Z., "Comparison of F/A-18A Inlet Flow Analyses with Flight Data Part 1," Journal of Aircraft, Vol. 33, No. 3, 1996, pp. 457-462.

[38] Pike Farr, A., "Evaluation of F-15 Inlet Distortion," Journal of Aircraft, Vol. 13, No. 1, 1976, pp. 36-42.

[39] Burley, R. R., and Hwang, D. P., "Investigation of Tangential Blowing Applied to a Subsonic V/STOL Inlet," Journal of Aircraft, Vol. 20, No. 11, 1982, pp. 926-934.

[40] Erbsloh, S. D., Crowther, W. J., and Frutos, J. R., "Control of Compressor Face Total Pressure Distortion on a High Bypass Turbofan Intake Using Air-Jet Vortex Generators," AIAA Paper 2004-2206, 2004, p. 11.
[41] Daggett, D. L., Kawai, R., and Friedman, D., "Blended Wing Body Systems Studies: Boundary Layer Ingestion Inlets With Active Flow Control," NASA CR 2003-212670, 2003.

[42] Berrier, B. L., and Allan, B. G., "Experimental and Computational Evaluation of Flush-Mounted S-duct Inlets," AIAA Paper 2004-764, 2004.

[43] Moult, E. S., "De Havilland Engines-Some Recollections," The Aeronautical Journal, Vol. 82, Sept. 1978, pp. 369-386.

[44] Williams, T. L., and Hunt, B. L., "Top Inlet System Feasibility for Transonic-Supersonic Fighter Aircraft Applications," AIAA Paper 1980-1809, 1980, pp. 1-15.

[45] Gebhardt, G. T., "Acoustical Design Features of Boeing Model 727,' Journal of Aircraft, Vol. 2, No. 4, 1965, pp. 272-277.

[46] Condit, P. M., "Design Evolution of the Boeing 757," The Aeronautical Journal, Vol. 85, Dec. 1981, pp. 451-458.

[47] "Progress of NASA Research Relating to Noise Alleviation of Large Subsonic Jet Aircraft," Proceedings of a Conference Held at Langley Research Center, Hampton, Virginia, SP-189, NASA, Oct. 1968, pp. 1-673.

[48] Argyris, J. H., "The Impact of the Digital Computer on Engineering Sciences-Part 1," The Aeronautical Journal, Vol. 74, Jan. 1970, pp. 13-41.

[49] Black, S., "Composite Nacelles: Flying Towards New Horizons," High-Performance Composites, May 2004.

[50] Dawson, L. G., and Sills, T. D., "An End to Aircraft Noise? (with discussion)," The Aeronautical Journal, Vol. 76, May 1972, pp. 286297.

[51] Hodge, C. G., Winslow, L. J., and Wood, S. K., "The Effect of InletNoise Suppression on Propulsion System Design," AIAA Paper 1973 1294, 1973, p. 17.

[52] Regan, B., and Eaton, J., "Modelling the Influence of Acoustic Liner Nonuniformities on Duct Modes," Journal of Sound and Vibration, Vol. 219, No. 5, 1999, pp. 859-879.

[53] McAlpine, A., and Wright, M., "Acoustic Scattering by a Spliced Turbofan Inlet Duct Liner at Supersonic Fan Speeds,” Journal of Sound and Vibration, Vol. 292, Nos. 3-5, 2006, pp. 911-934.

[54] Norris, G., "Power House," Flight International, Vol. 169, No. 5040, 2006, pp. 42-44.

[55] Jones, M. G., Tracy, M. B., Watson, W. R., and Parrott, T. L., "Effects of Liner Geometry on Acoustic Impedance," AIAA Paper 2002-2446, 2002.

[56] Bielak, G. W., Premo, J. W., and Hersh, A. S., "Advanced Turbofan Duct Liner Concepts,” NASA Report CR-1999-209002, 1999.

[57] Nallasamy, M., "Computation of Noise Radiation from Fan Inlet and Aft Ducts," Journal of Aircraft, Vol. 34, No. 3, 1997, pp. 387-393.

[58] Pan, F. L., and Coupland, J., "An Integrated Optimization System for Low Noise Nacelle Design,” AIAA Paper 2005-2942, 2005.

[59] Lafronza, L., Song, W., McAlpine, A., Astley, R. J., and Keane, A. J., "Liner Optimization Using a Hybrid Finite Element Method," Proceedings of the 6th European Turbomachinery Conference, Vol. 2, ETC, Rhode-Saint-Genese, Belgium, 2005, pp. 1085-1095.

[60] Envia, E., "Fan Noise Reduction: An Overview," AIAA Paper 20010661, 2001, p. 16.

[61] Smith, A. R., Thorne, R. C. G., Surply, T., and Chanez, P., "Aerodynamic Aspects of Application of Negative Scarf Intake to High Bypass Ratio Civil Turbofans," AIAA Paper 2005-4205, 2005, p. 11.

[62] Gerhold, C. H., and Clark, L. R., "Effect of Blowing on Boundary Layer of Scarf Inlet," NASA, Report TM-2004-213267, 2004.

[63] Throndson, L., "Combat Survivability with Advanced Aircraft Propulsion Development," Journal of Aircraft, Vol. 19, No. 11, 1982, pp. 915-920.

[64] Haddad, R. C., Bingaman, D. C., Surber, L. E., and Bare, E. A., "The Impact of LO-Configured Forebodies on Inlet Approach Flowfields," AIAA Paper 1991-2599, 1991, pp. 1-23.

[65] Kuhn, R. E., "Design Concepts for Minimizing Hot-Gas Ingestion in V/ STOL Aircraft," Journal of Aircraft, Vol. 19, No. 10, 1982, p. 845.

[66] Behrouzi, P., and McGuirk, J. J., "Particle Image Velocimetry for Intake Ingestion in Short Takeoff and Landing Aircraft," Journal of Aircraft, Vol. 37, No. 6, 2000, pp. 994-1000.

[67] Saddington, A. J., and Knowles, K., "Jet/Intake Interference in Short Takeoff, Vertical Landing Aircraft," Journal of Aircraft, Vol. 38, No. 5, 2001, pp. 924-931.

[68] Bennett, H. W., "The Development of the Composite Material Engine Nacelle," The Aeronautical Journal, Vol. 84, July 1980, pp. 209-213.

[69] Leyland, D. C., "Intake Design for Strike/Fighter Aircraft," Practical Intake Aerodynamic Design, edited by E. L. Goldsmith and J. Seddon, Blackwell Scientic Publications, Oxford, 1993.

[70] Young, L. C., and Beaulieu, W. D., "Review of Hammershock Pressures in Aircraft Inlets," Journal of Aircraft, Vol. 12, No. 4, 1975, 


$$
\text { p. } 210 .
$$

[71] Evans, P. J., and Truax, P. P., "YF-16 Air Induction System Design Loads Associated with Engine Surge," Journal of Aircraft, Vol. 12, No. 4, 1975, p. 205.

[72] Menzies, R. D. D., Babcock, K. J., Barakos, G. N., and Richards, B., "Surge Wave Propagation Modelling Using Computational Fluid Dynamics," AIAA Paper 2003-4088, 2003, p. 1.

[73] Ytterstrom, A., and Axelson, E., "Hammershock Calculations in the Air Intake of JAS 39 GRIPEN, Using Dual Timestepping," AIAA Paper 99-3113, 1999, pp. 1-9.

[74] Goble, B. D., King, S., Terry, J., and Schoop, M., "Inlet Hammershock Analysis Using a 3-D Unsteady Euler/Navier-Stokes Code," AIAA Paper 96-2547, 1996.
[75] Gridley, M., Sylvester, T., and Truax, P., "Impact of a Probabilistic Approach on Inlet Hammershock Design Loads," AIAA Paper 992114, 1999, p. 1.

[76] Newsome, R. W., "Numerical Simulation of Near-Critical and Unsteady, Subcritical Inlet Flow,” AIAA Journal, Vol. 22, No. 10, 1984, p. 1375.

[77] McCallum, B. N., "F-16 Inlet Stability Investigation," AIAA Paper 89$2465,1989$.

[78] Choby, D. A., "Tolerance of Mach 2.50 Axisymmetric Mixed Compression Inlet to Upstream Flow Variations," NASA TM X-2433, 1972.

[79] Zha, G., Knight, D., and Smith, D., "Investigations of High-Speed Civil Transport Inlet Unstart at Angle of Attack," Journal of Aircraft, Vol. 35, No. 6, 1998, pp. 851-856. 